\title{
The Effect of Developing the Muscular Balance of the Arms' Muscles on Some of the Mechanical Basics and Digital Level in Hammer Throw
}

\author{
Raafat Abdel-Monsef Aly ${ }^{1}$ \\ ${ }^{1}$ Assistant Professor, Track and Field Events Training Department, Faculty of Physical Education for Boys, Alexandria \\ University, Egypt
}

\begin{abstract}
This study aimed at identifying the effect of developing the muscular balance of the arms' muscles on some of the mechanical basics and the digital level of hammer throw contestants. The researcher used the experimental method on the sample of 16 students from the Faculty of Physical Education for Boys - Alexandria University who have previously learned the hammer throw competition and have the best records. The post-measurements were conducted on them and they were divided into two equal groups, of which the first is the control group and the other is the experimental group, each one of them consisted of 8 students and had the same training program applied on them with the same size and intensity with the varied size of training given to the weak muscles, according to the strength of the anterior and posterior muscles, which was approximately 2:3, so the weak muscles were given a training size of 3:2 to the posterior muscles in the experimental group, in order to develop the muscular balance of the arms' muscles. The study was applied for 8 weeks with 4 times per-week (2, technical), (2, weights), finally the post-measurements were conducted on both groups and statistically treated.

Conclusions: Developing the muscular balance affected positively the improvement of mechanical basics and the digital level in hammer throw. The muscular balance of the experimental group was better than that of the control group, as the difference between the balance of the right arm was $20.2 \%$ and that of the left arm was $25.2 \%$, while the balance of both arms together was $14 \%$. The difference between the percentages of the mechanical improvement of the speed of release was $8.71 \%$, the increase of release height was $2.50 \%$, the release angle was $9.07 \%$, and the difference between the improvements of the hammer throw distance was 5.54\%, in favor to the experimental group.
\end{abstract}

Recommendations: Muscular balance should be developed in all parts of the body in all of the track and field events.

\section{Introduction and Research Problem}

$\mathrm{H}$ ammer throw is one of the competitions that require high accuracy of compatibility and coordination through the stages of technical performance with the appropriate direction of the final effort while taking into consideration the mechanical basics of performance. $(4: 2)$

The mechanical aspect of hammer throw is based on increasing the speed of the hammer while maintaining the dynamic balance, therefore, the mechanical basics of hammer throw should be used as much as possible, the most important of which is the height of the releasing point. (1:16)
The technical performance of hammer throw requires the use of strengths of the different parts of the body with the compatibility of movements where the correct technique depends on the maximum speed of the hammer while releasing it. (9:69)

The releasing stage is one of the most important stages of technical performance in hammer throw, as the effect of all powers involved in the movement which increases the speed should all end at the same moment. (13:35)

The muscular balance is very important for the athlete because it protects him from injuries and enhances his physical level, so every training session should involve the muscular balance exercises for the working muscles and the corresponding ones. (15:69) 
The balance of muscular strength is one of the main and important factors that promote the digital and physical level of the contestants. (18:42) (10:178)

The muscular balance is the relative balance between the strength of the corresponding muscles around the joint as well as the ability and the muscular endurance. $(5: 10)(11: 109)$

The muscular balance also depends on the efficiency of the work of the musculoskeletal system through its ability to work correctly on the balance in the production of power between the working muscles and the corresponding muscles. (11:216)

The lack of muscular balance leads to an increase in the strength of the working muscles without increasing the strength of the corresponding muscle which makes them vulnerable to injury and therefore adversely affect the performance of the athlete. $(2: 7)(3: 38)$

The lack of muscular balance also leads to a lack of smooth performance, which negatively affects the level of achievement. (12:47) (14:30)

So when designing the strength programs it is important to choose the exercises that strengthen the muscle groups on both sides of the body and on both sides of the joint to develop the ability of muscles to produce the maximum strength in the maximum range of movement with the highest possible rate of speed $(7: 158,159)$

It is also important to focus on developing the muscular balance in all training programs and this is done by using weight training programs correctly. (20:78)

Weight training can increase strength and improve the technical performance because it increases the size of each muscle fiber and changes the muscle protein. $(8: 44)$

\section{Research Objective}

Identifying the effect of developing the muscular balance of the arms' muscles on some of the mechanical basics and the digital level in hammer throw

\section{Research Hypotheses}

- Muscular balance positively affects some of the mechanical basics in hammer throw.

- Muscular balance positively affects the digital level in hammer throw.

\section{Research Procedures}

The study was conducted for 8 weeks with 4 times per week in the period from 19/3/2016 until 12/5/2016. The researcher used the experimental method on the research sample using the post-measurements and a 60 cadres/sec. video camera from the top vertically on the circle of throwing and the second was vertical on the throwing circle. The training program was applied on the two groups with the same intensity and size with the varied size of training given to the weak muscles in the experimental group, according to the strength of the anterior and posterior muscles, which was approximately $2: 3$, so the weak muscles were given a training size of $3: 2$ to the posterior muscles, in order to develop the muscular balance of the arms' muscles.

\section{Research Sample}

The sample was selected purposively from the Faculty of Physical Education for Boys - Alexandria University, they all were under-20 years, have previously learned the hammer throw competition and achieved the best records. They were 16 students and were divided into two equal groups, one of which is the control group and the other is the experimental group, each consisted of 8 students. 
Table (1)

The arithmetic mean, the calculated $(t)$ value and the improvement percentage between the pre- and post-measurements of the control group in the research variables

\begin{tabular}{|c|c|c|c|c|c|c|c|}
\hline \multirow{2}{*}{ Measurements } & \multicolumn{2}{|c|}{ Pre-measurement } & \multicolumn{2}{|c|}{ Post-measurement } & \multirow{2}{*}{$\begin{array}{l}\text { Difference } \\
\text { between the } \\
\text { two means }\end{array}$} & \multirow{2}{*}{$\begin{array}{l}\text { Calculated } \\
\text { "t" value }\end{array}$} & \multirow{2}{*}{$\begin{array}{l}\text { Percentage of } \\
\text { improvement } \%\end{array}$} \\
\hline & $\mathbf{x -}$ & $\pm \mathbf{p}$ & $x-$ & $\pm \mathbf{p}$ & & & \\
\hline $30 \mathrm{~m}$ run (sec.) & 4.22 & 0.06 & 3.93 & 0.12 & -0.30 & $5.78^{*}$ & -7.04 \\
\hline Vertical jump (cm) & 52.0 & 3.34 & 61.50 & 2.98 & 9.00 & $7.73 *$ & 17.14 \\
\hline Wide jump $(\mathrm{cm})$ & 250.25 & 9.65 & 261.13 & 7.77 & 10.88 & $11.41^{*}$ & 4.35 \\
\hline $5 \mathrm{~kg}$ shot put forward $(\mathrm{kg})$ & 11.68 & 0.55 & 12.28 & 0.48 & 0.61 & $6.82 *$ & 5.19 \\
\hline $5 \mathrm{~kg}$ shot put backward (kg) & 12.46 & 0.56 & 13.06 & 0.49 & 0.61 & $6.22 *$ & 4.87 \\
\hline Right arm forward (kg) & 40.50 & 4.17 & 52.13 & 5.84 & 11.63 & $16.48^{*}$ & 28.70 \\
\hline Right arm backward (kg) & 28.13 & 3.23 & 35.25 & 4.37 & 7.13 & $10.69^{*}$ & 25.33 \\
\hline Balance of the right arm & 69.54 & 4.97 & 67.67 & 4.40 & -1.87 & 2.13 & -2.69 \\
\hline Left arm forward $(\mathrm{kg})$ & 32.13 & 2.95 & 43.38 & 3.70 & 11.25 & $14.55^{*}$ & 35.02 \\
\hline Left arm backward (kg) & 24.13 & 3.00 & 29.63 & 3.34 & 5.50 & $10.29 *$ & 22.80 \\
\hline Balance of the left arm & 75.05 & 5.62 & 68.37 & 5.94 & -6.68 & $4.15^{*}$ & -8.90 \\
\hline Both arms forward (kg) & 81.25 & 10.11 & 98.50 & 10.60 & 17.25 & $17.99^{*}$ & 21.23 \\
\hline Both arms backward (kg) & 57.63 & 4.31 & 69.13 & 3.23 & 11.50 & $16.88^{*}$ & 19.96 \\
\hline Balance of both arm & 71.47 & 6.12 & 70.69 & 6.11 & -0.78 & 1.01 & -1.09 \\
\hline Releasing velocity (m/sec.) & 16.24 & 1.39 & 17.43 & 1.13 & 1.20 & $8.33 *$ & 7.38 \\
\hline Height of release $(\mathrm{cm})$ & 173.38 & 3.78 & 180.00 & 3.07 & 6.63 & $6.88^{*}$ & 3.82 \\
\hline Angle of release (degree) & 31.09 & 1.72 & 32.40 & 1.63 & 1.31 & $12.19^{*}$ & 4.22 \\
\hline Distance of the hammer (m) & 31.50 & 2.33 & 33.88 & 1.89 & 2.38 & $7.33 *$ & 7.54 \\
\hline
\end{tabular}

* tabular "t" significant at $0.05=2.365$

Table (2)

The arithmetic mean, the calculated ( $t)$ value and the improvement percentage between the pre- and post-measurements of the experimental group in the research variables

\begin{tabular}{|c|c|c|c|c|c|c|c|}
\hline \multirow{2}{*}{ Measurements } & \multicolumn{2}{|c|}{ Pre-measurement } & \multicolumn{2}{|c|}{ Post-measurement } & \multirow{2}{*}{$\begin{array}{c}\text { Difference } \\
\text { between the two } \\
\text { means }\end{array}$} & \multirow{2}{*}{$\begin{array}{c}\text { Calculated "t" } \\
\text { value }\end{array}$} & \multirow{2}{*}{$\begin{array}{c}\text { Percentage of } \\
\text { improvement \% }\end{array}$} \\
\hline & $\mathbf{x -}$ & $\pm \mathbf{p}$ & $x-$ & $\pm \mathbf{p}$ & & & \\
\hline $30 \mathrm{~m}$ run $(\mathrm{sec})$. & 4.23 & 0.09 & 3.93 & 0.15 & -0.30 & $9.24 *$ & -7.10 \\
\hline Vertical jump $(\mathrm{cm})$ & 50.38 & 3.85 & 60.75 & 2.96 & 10.38 & $17.42 *$ & 20.60 \\
\hline Wide jump (cm) & 248.25 & 6.65 & 260.25 & 4.37 & 12.00 & $10.17^{*}$ & 4.83 \\
\hline $5 \mathrm{~kg}$ shot put forward $(\mathrm{kg})$ & 11.63 & 0.48 & 12.79 & 0.54 & 1.16 & $13.86^{*}$ & 9.99 \\
\hline $5 \mathrm{~kg}$ shot put backward (kg) & 12.43 & 0.42 & 13.68 & 0.48 & 1.26 & $13.20^{*}$ & 10.11 \\
\hline Right arm forward (kg) & 39.38 & 3.38 & 48.88 & 5.30 & 9.50 & $11.53^{*}$ & 24.13 \\
\hline Right arm backward (kg) & 27.13 & 3.56 & 39.63 & 4.63 & 12.50 & $15.17 *$ & 46.08 \\
\hline Balance of the right arm & 68.95 & 7.48 & 81.22 & 5.78 & 12.27 & $6.00 *$ & 17.79 \\
\hline Left arm forward $(\mathrm{kg})$ & 30.88 & 2.36 & 38.63 & 3.11 & 7.75 & $13.13^{*}$ & 25.10 \\
\hline Left arm backward (kg) & 23.38 & 2.83 & 33.00 & 3.51 & 9.63 & $18.08^{*}$ & 41.18 \\
\hline Balance of the left arm & 75.71 & 7.26 & 85.67 & 8.75 & 9.96 & $4.03^{*}$ & 13.15 \\
\hline Both arms forward (kg) & 80.25 & 6.71 & 93.13 & 8.84 & 12.88 & $10.46^{*}$ & 16.04 \\
\hline Both arms backward (kg) & 56.88 & 3.72 & 74.63 & 3.78 & 17.75 & $17.83^{*}$ & 31.21 \\
\hline Balance of both arm & 71.02 & 3.37 & 80.59 & 6.56 & 9.56 & $5.33^{*}$ & 13.47 \\
\hline Releasing velocity (m/sec.) & 15.87 & 1.48 & 18.95 & 1.36 & 3.09 & $20.35^{*}$ & 19.44 \\
\hline Height of release $(\mathrm{cm})$ & 172.63 & 3.29 & 184.50 & 3.30 & 11.88 & $40.25^{*}$ & 6.88 \\
\hline Angle of release (degree) & 31.04 & 1.82 & 35.34 & 1.46 & 4.30 & $7.08 *$ & 13.85 \\
\hline Distance of the hammer (m) & 31.13 & 2.23 & 35.75 & 2.66 & 4.63 & $14.28 *$ & 14.86 \\
\hline
\end{tabular}

* tabular "t" significant at $0.05=2.365$ 
Table (3)

The arithmetic mean, the calculated $(t)$ value and the improvement percentage between the pre- and post-measurements of (the control and experimental groups) in the research variables

\begin{tabular}{|c|c|c|c|c|c|c|c|}
\hline \multirow{2}{*}{ Measurements } & \multicolumn{2}{|c|}{ Pre-measurement } & \multicolumn{2}{|c|}{ Post-measurement } & \multirow{2}{*}{$\begin{array}{c}\text { Difference } \\
\text { between the two } \\
\text { means }\end{array}$} & \multirow{2}{*}{$\begin{array}{l}\text { Calculated " } t \text { " } \\
\text { value }\end{array}$} & \multirow{2}{*}{$\begin{array}{l}\text { Percentage of } \\
\text { improvement } \%\end{array}$} \\
\hline & $\mathbf{x}-$ & $\pm \mathbf{p}$ & $\mathbf{x}-$ & $\pm \mathbf{p}$ & & & \\
\hline $30 \mathrm{~m}$ run (sec.) & 3.925 & 0.15 & 3.926 & 0.12 & -0.001 & 0.019 & -0.03 \\
\hline Vertical jump (cm) & 60.75 & 2.96 & 61.50 & 2.98 & -0.75 & 0.505 & -1.22 \\
\hline Wide jump (cm) & 260.25 & 4.37 & 261.13 & 7.77 & -0.88 & 0.278 & -0.34 \\
\hline $5 \mathrm{~kg}$ shot put forward $(\mathrm{kg})$ & 12.79 & 0.54 & 12.28 & 0.48 & 0.51 & 1.996 & 4.17 \\
\hline $5 \mathrm{~kg}$ shot put backward (kg) & 13.68 & 0.48 & 13.06 & 0.49 & 0.62 & $2.550^{*}$ & 4.74 \\
\hline Right arm forward (kg) & 48.88 & 5.30 & 52.13 & 5.84 & -3.25 & 1.165 & -6.24 \\
\hline Right arm backward (kg) & 39.63 & 4.63 & 35.25 & 4.37 & 4.38 & 1.945 & 12.41 \\
\hline Balance of the right arm & 81.22 & 5.78 & 67.67 & 4.40 & 13.55 & $5.273 *$ & 20.02 \\
\hline Left arm forward $(\mathrm{kg})$ & 38.63 & 3.11 & 43.38 & 3.70 & -4.75 & $2.778^{*}$ & -10.95 \\
\hline Left arm backward (kg) & 33.00 & 3.51 & 29.63 & 3.34 & 3.38 & 1.973 & 11.39 \\
\hline Balance of the left arm & 85.67 & 8.75 & 68.37 & 5.94 & 17.30 & $4.626^{*}$ & 25.30 \\
\hline Both arms forward (kg) & 93.13 & 8.84 & 98.50 & 10.60 & -5.38 & 1.102 & -5.46 \\
\hline Both arms backward (kg) & 74.63 & 3.78 & 69.13 & 3.23 & 5.50 & $3.131^{*}$ & 7.96 \\
\hline Balance of both arm & 80.59 & 6.56 & 70.69 & 6.11 & 9.90 & $3.123^{*}$ & 14.00 \\
\hline Releasing velocity (m/sec.) & 18.95 & 1.36 & 17.43 & 1.13 & 1.52 & $2.436^{*}$ & 8.71 \\
\hline Height of release $(\mathrm{cm})$ & 184.50 & 3.30 & 180.00 & 3.07 & 4.50 & $2.826^{*}$ & 2.50 \\
\hline Angle of release (degree) & 35.34 & 1.46 & 32.40 & 1.63 & 2.94 & $3.806^{*}$ & 9.07 \\
\hline Distance of the hammer (m) & 35.75 & 2.66 & 33.88 & 1.89 & 1.88 & 1.627 & 5.54 \\
\hline
\end{tabular}

\section{Discussion of the Results}

Tables (1) and (2) show that there are significant differences between the pre- and post-measurements of the control and experimental groups in favor to the postmeasurements regarding the balance of the both arms forward and backward.

The researcher points that this is due to the use of the exercises in the training program for the control group which included ground exercises and weight training, and this is consistent with what Raafat Abdel-Monsef when he said that weight training leads to the development of muscular strength, which positively affects the level of the produced power and thus positively affects the level of performance. (5)

The exercises of the training program improved the strength of the contestants, which led to the improvement of some of the mechanical basics in hammer throw, which was positively reflected on the digital level of the hammer throw.

This is also evident in the improvement percentage for all physical and mechanical variables and the distance of hammer release.

Table (3) which illustrates the arithmetic mean, the calculated $(\mathrm{t})$ value and the improvement percentage between the pre- and post-measurements of the control and experimental groups in the research variables shows that there are significant differences in the variables of (backward throw - releasing speed - height of release angle of release) in favor to the experimental group.

Although the other variables of the study did not show significant differences between them the percentage of improvement of these variables were better in the experimental group than the percentage of improvement in the control group.

The researcher shows that this is due to developing the muscular balance of the arms in the experimental group and not in the control group, which positively reflected on the physical variables, mechanical basics and the digital level of the hammer in favor to the experimental group.

Muscular balance is important for all muscle groups because the lack of muscular balance leads to physical and technical delays. (10)

The lack of muscular balance decreases the extent of movement of the joints, and impedes the level of strength, speed and compatibility. (1)

This is in line with what has been recommended to give more concerns to the development of muscular balance around all joints of the body. (5) (6) 
Muscular balance is very important for the athlete as it enhances the physical level, and it should be included in each training session of the muscular balance exercises for the working muscles and the corresponding muscles. (15)

That was taken into account by the researcher in his study trying to develop the muscular balance of the arms' muscles of the hammer throw athletes and to strengthen the light muscles around the joint as the lack of muscular balance in which the muscle group around a particular joint makes it tougher than the corresponding muscle group around the same joint. (2)

This is consistent with what was recommended to increase training on the weak muscles that may cause the lack of muscular balance around the joint when designing the training program. (21)

The study focused on the weak muscles of the arms and tried to improve the balance between them and the tougher muscles corresponding to the same joint, which improved the strength of the competitors and thus improved the mechanical basics that have positively affected the level of hammer throw.

In order to perform the hammer throw successfully, this requires performing according to the mechanical basics of the throw from an optimal angle at $45^{\circ}$, with a height of the releasing point, appropriate speed and the required power. (17)

From the above, we find that the results obtained have achieved the hypothesis of the research, which showed the importance of muscular balance and its positive effect on the mechanical basics and the digital level in hammer throw.

\section{Conclusions}

1- Muscular balance improved the physical variables and the level of produced power.

2- Muscular balance improved some of the mechanical basics in hammer throw.

3- Muscular balance improved the digital level for the hammer throw contestants.

\section{Recommendations}

1- It is important to develop the muscular balance of the arms and the legs as well in the hammer throw event.

2- Further studies which concern with the muscular balance of all of the working muscles and the corresponding muscles of the body in the rest of track and field events should be taken into consideration.

\section{References}

1- Abou-Elela Ahmed Abdel-Fattah: Sport Training, Physiological Basics, Dar Al-Fikr Al-Araby, Cairo, 1997.

2- El-Amir Abdel-Sattar Hassan: The Effect of Developing the Muscular Balance of the Lower Limb Muscles on Some Special Physical Variables and the Digital Level of Triple Jump Athletes, unpublished Master's thesis, Faculty of Physical Education, Asyut University, 2013.

3- Tamer Emad-Eldin Said: Percentages of the Muscular Balance and Their Relationship to the Performance Level of Wrestlers, unpublished $\mathrm{PhD}$ thesis, Faculty of Physical Education for Boys, Benha University, 2012.

4- Khaled Wahid Ibrahim: The Effect of Using the Releasing Curve on the Path of Release in Hammer Throw for Amateurs, unpublished PhD thesis, Faculty of Physical Education for Boys, Alexandria University, 2003.

5- Raafat Abdel-Monsef Aly: The Effect of Developing the Motor and Muscular Balance on the Lateral Deviations on the Distance of the Triple Jump, unpublished $\mathrm{PhD}$ thesis, Faculty of Physical Education for Boys, Alexandria University, 2004.

6- Raafat Abdel-Monsef Aly: A Comparative Study of the Effect of Muscular Balance of the Legs in Different Percentages on the Muscular Strength and Technical Performance of the Triple Jump Athletes, published research, Journal of Research, Faculty of Physical Education for Boys, Zagazig University, 2008.

7- Abdel-Aziz Ahmed El-Nemr: Effect of Strength Balance between the Flexor Muscles and Extensor Muscles of the Knee Joint on the Running Speed, Scientific Journal of Physical Education and Sports, No. 18 Faculty of Physical Education for Boys, Cairo, 1993.

8- Abdel-Aziz El-Nemr, Nariman El-Khatib: Physical Preparation and Weight Training for Juniors, First Edition, 2000.

9- Andreas, V. : Reassessing Velocity Generation in Hammer throwing, IAAF 24,4.2002

10- Brain, S., : Fitness Illustrated, Human Kinetics, P, cm. 2011. 
11- Brian, J.S : Steven, E : Sport Physiology for Coaches Vol. 10. Human Kinetics. U.S.A, 2006.

12- Christopher, W. Digiovanni, J, : Core Knowledge in U.S.A, 2007.

13- Dapena, J., Some Biome chanical Aspects of Hammer Throwing, Track Technique No, 111, Spring, 1999.

14- Gill, S. Vardita. G. Eli,A, : Postural disorders and muscle skeletal dysfunction Prevention and treatment, 2ed Elsevier Health Sciences, 2008.

15- Mark, K. Paul, R, : ten nis anatomy, hu, man, kin et,ics, 2011.

16- Jensen, P., : Throwing The Hammer, Event Gash Hammer, January, 2000.
17- Jermy, M, Burgess, A, Feasey, C., Lensen N,Willis.c Tucher, Syme, R, : Avariable drag Coefficient, Spatially extended numerical model of hammer throws and new wind tunnel data on current hammers sports Eng, 2014.

18- Jim clover : Sports Medicine essentials core concepts in athletic training \& Fitness instruct ion 2nd edition, 2007

19- Jon, C. Client - Centered Exercise Prescription, Human Kinetics, U.S.A, 2014.

20- Josph, M, M., : Strength Training for women only. How to Double your Strength in only 6 Weeks, Universe, Inc., 2003.

21-Tomas, B. Roger, E, : Essentials of Strength Training and Conditioning 3ed Human Kinetics, 2008. 